\title{
Effects of nutrition, growth hormone disturbances, training, altitude and sleep on lung volumes
}

\author{
C. Gaultier*, R. Crapo**
}

\section{CONTENTS}

\begin{tabular}{|c|c|}
\hline Ing volumes & \\
\hline Inadequate nutrition and lung growth in animals & 2913 \\
\hline 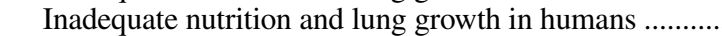 & 2914 \\
\hline Effe & 2914 \\
\hline Ove & 2914 \\
\hline Overnutrition and lung volumes in children & .. 2914 \\
\hline $\begin{array}{l}\text { Effect of growth hormone disturbances } \\
\text { on lung volumes }\end{array}$ & \\
\hline & 291 \\
\hline $\begin{array}{l}\text { Lung volumes in patients with excessive growth } \\
\text { hormone }\end{array}$ & \\
\hline
\end{tabular}

Various modulating factors have been shown to affect postnatal lung growth and development in humans and other mammalian species. Therefore, normative pulmonary function data should ideally indicate the environmental conditions of life. This paper will review current knowledge on the effects of nutrition, growth hormone disturbances, training and altitude on lung volumes in children and adults. Furthermore, the impact of sleep states on lung volumes is considered. The present review is a background paper of a consensus document on measurements of lung volumes in humans.

\section{Effect of nutrition on lung volumes}

Our knowledge of the effect of disturbances in nutrition, either inadequate nutrition or overnutrition, on lung growth has been provided mainly by animal studies.

\section{Inadequate nutrition and lung growth in animals}

The effects of inadequate nutrition on lung volumes have been studied in two species with differing lung maturity at birth: in rats, which have immature lungs at birth; and guinea-pigs, in which lung growth is advanced at birth.

In rats, the adverse effects of inadequate foetal nutrition can be summarized as follows: nutritional status during pregnancy affects foetal lung growth, with a greater effect in late pregnancy resulting in small and hypocellular lungs
Effect of training on lung volumes

Effect of swimming on lung volumes in children and

young adults

Effects of other sports and of enhanced physical

education in children ................................................... 2915

Effects of sporting activity in adults ............................. 2916

Effects of ventilatory muscle training in adults ............... 2916

Effect of altitude on lung volumes ................................... 2916

Effects of sleep on lung volumes .................................... 2917

Data available in adults ........................................... 2917

Data available in newborns .............................................. 2917

at birth [1]. Inadequate nutrition during the first 21 days of life is associated with a decrease in cell division [2], diminished alveolar formation, smaller lung volumes, and decreased accumulation of elastin [3, 4]. This is especially marked with insufficient protein nutrition $[3,4]$. Late postnatal nutritional insufficiency after weaning affects cell size, but not cell division [5]. The structure of the lung parenchyma of rats restricted in protein during early and late postnatal periods has been studied after refeeding for 11 weeks. All parenchymal subcomponents grew consistently with normal volume and surface densities $[6,7]$ as compared to controls, indicating that recovery occurs after refeeding.

In guinea-pigs, the greatest effects of nutritional insufficiency occur prenatally. Prenatal starvation is associated with a dramatic decrease in neonatal survival rate, and airspace volume is significantly reduced in live neonates [8]. Despite normal postnatal feeding, residual reductions in alveolar surface area persist. The effects of neonatal and weaning starvation on lung growth are less marked; and after refeeding, full recovery in lung dimensions is noted in adulthood [9].

Vitamin D deficiency in dams and pups induces rickets in young rats, and rachitic rats have low lung weight and lung compliance [10]. These data raise the question of the role of vitamin D deficiency in respiratory disorders accompanying fat soluble vitamin malabsorption syndromes.

*Service de Physiologie, Hôpital Robert Debré, Université Paris VII, Paris, France. **Pulmonary Divisions, LDS Hospital and University of Utah, Salt Lake City, Utah, USA.

Correspondence: C. Gaultier, Dept of Physiology, Hôpital Robert Debré, 48 Boulevard Sérurier, 75019 Paris, France.

Keywords: Adults, children, development, lung volumes, swimming.

Received: August 11 1997; accepted for publication September 71997

This background paper was developed from a workshop on measurement of lung volumes supported by the American Thoracic Society and the National Heart, Lung and Blood Institute (Conference Grant No. R13 HL48384-01). 


\section{Inadequate nutrition and lung growth in humans}

Conflicting data have been reported on the effect of intrauterine growth retardation on lung volumes in children. CHAN et al. [11] found that vital capacity (VC) was normal in children of low birth weight, whereas RoNA et al. [12] reported that forced vital capacity (FVC) was decreased after adjustment for gestational age, parental smoking, and social factors.

To the best of our knowledge, no functional and/or postmortem lung volume data are available for insufficiently nourished infants during the postnatal active period of alveolar multiplication and elastin accumulation, i.e. the first $2 \mathrm{yrs}$ of life [13-16]. We may speculate that adverse effects will be greatest in humans when nutritional insufficiency occurs during late gestation and the first 2 yrs of life. Adverse effects of inadequate nutrition on the development of lung function in the growing human lung may be expected to be associated with low lung volumes and low lung compliance, and an increased ratio of maximal expiratory flow rate to lung volume. This speculation is supported by functional data reported in postnatally inadequately nourished hamsters, in which maximum expiratory flow at $50 \%$ of the $\mathrm{VC}\left(V^{\prime} \max , 50\right)$ was half that found in control animals. However, since VC was dramatically diminished in inadequately nourished hamsters, when $V^{\prime} \max , 50$ was expressed in relation to $\mathrm{VC}$, it was much greater in inadequately nourished animals than in controls [17]. Thus, when postnatal alveolarization is suppressed, relative airflows are high. The lung growth pattern related to nutritional insufficiency is the direct opposite of the lung growth disorders caused by hypoxia at high altitudes, where alveolar growth is increased [18] and associated with disproportionate lung-to-airway size [19].

The functional data available in humans concern inadequately nourished school children [20]. Thirty wasted children, with a weight less than $80 \%$ predicted for height, indicating acute nutritional insufficiency were studied. In addition, 135 stunted children, who had been inadequately nourished in the past, were studied. Peak expiratory flow (PEF) rate was the only mechanical parameter measured. PEF was not decreased in stunted children, indicating that previous nutritional insufficiency does not disturb growthrelated increases of PEF, whereas PEF was decreased in wasted children, presumably because of muscle weakness. Future investigations, which compare normally and inadequately nourished growing infants and children of identical racial groups, should include lung function development with regards to lung volume, lung compliance, and relative flow rates. Furthermore, effects of refeeding in inadequately nourished children should be investigated.

The effects of nutritional insufficiency and refeeding on lung volumes and diaphragmatic contractile properties were studied in severely inadequately nourished patients with anorexia nervosa [21]. Fifteen female patients were studied at a mean $( \pm \mathrm{SD})$ age of $24.9( \pm 8.7)$ yrs. FVC and forced expiratory volume in one second (FEV1) were in the low normal range upon hospital admission, and increased significantly with a nutritional support of 30 days. Other lung volumes did not change. Diaphragmatic function was reduced initially and increased with nutrition.

\section{Effect of nutritional changes on lung volumes}

Information is scarce with regard to the potential effects of generational changes in diet, such as migrant populations. RAven et al. [22] have shown that third-generation Japanese-Americans have lung volume corrected for hei-ght more comparable to Caucasians than native Japanese. MASSEY and FouRNIER-MASSEY [23] studied Japanese-Ame-ricans aged $20-80$ yrs. With regards to anthropometry and pulmonary function, they observed that younger Japan- eseAmericans resembled Caucasians more, and older Japanese-Americans resembled the Japanese from Japan. However, environmental factors other than changes in diet may occur in migrant populations to explain anthropome-tric and pulmonary function changes.

\section{Overnutrition and lung growth in animals}

Obesity induced by a high fat diet in male newborn rats alters biochemical properties of the lung and leads to structural changes [24]. At 8 weeks of age, obese rats display a significant increase in fixed lung volumes and in ratio of lung volumes to body weight and to body length ${ }^{3}$, with enlarged alveoli compared to controls but a normal total number of alveoli [25].

\section{Overnutrition and lung volumes in children}

Few studies have addressed the question of the effects of obesity on pulmonary function in children. In obese children with $135-140 \%$ and $125-205 \%$ ideal body weight (IBW), lung volumes were normal [26, 27]. In more markedly obese children (147-300\% IBW), a significant reduction in expiratory reserve volume was reported [28]. In the latter study, other lung volumes and maximal static pressure were normal, but expiratory flow rates and single breath diffusing capacity were decreased [28].

\section{Effect of growth hormone disturbances on lung volumes}

The effects of decreased growth hormone on lung volumes have been studied in children [29, 30] and adults $[31,32]$. Studies in adults have related to excessive levels of growth hormone [32-34].

\section{Lung volumes in growth hormone deficiency}

In children who had a growth hormone deficiency, VC, functional residual capacity (FRC), and total lung capacity (TLC) were appropriate for the small statures of the patients $[29,30]$. In children studied before and after treatment with human growth hormone, compensatory growth occurred, associated with increases in TLC and VC appropriate for the linear growth $[29,30]$.

In growth hormone deficient children, appropriate lung volumes for their small statures were associated with a low lung elastic recoil for their age [30], high carbon monoxide diffusion constants for their age [30], and closing volume and arterial partial pressure of oxygen in relation to their age [29]. 
Patients with adult onset hypopituitarism were found to have reduced lung volumes [31]. One study reported increased lung elastic recoil [31]. However, in another study, the pressure-volume relationship of the lung was normal when lung volume was related to the measured TLC [32]. Inspiratory muscle strength, airflows and gas exchange were normal [31, 32].

\section{Lung volumes in patients with excessive growth hormone}

In acromegalic adults, all lung volumes are increased in relation to standing height [32-34]. Despite the large lung volumes, diffusing capacity was normal [33, 34], suggesting an increase in the size of alveoli [33]. However, it has been argued that the transfer factor of the lung for carbon monoxide (TL,CO) may not be reliable for the interpretation of the mechanisms of lung growth in cases of large lung volumes [34]. A recent study, confirming previous findings $[32,33]$ shows that pulmonary distensibility was normal [34] and suggests that large lung volumes of acromegalic patients should be achieved by an increase in alveolar number rather than an increase in size. However, only morphometric studies of the lungs of acromegalic subjects could answer the question of the mechanisms of alveolar changes, either hyperplasia or hypertrophy, related to excessive levels of growth hormone during adulthood.

Animal studies, either in growing guinea-pigs [35] or adult rats [36] treated with growth hormone, did not show disproportionate enlargement of the lungs. Growth hormone might be active only in diseases in which secreting tumours deliver large amounts of hormones [33, 37].

\section{Effect of training on lung volumes}

The animal studies available have provided conflicting data with regards to the effects of sustained exercise on enhancement of lung growth [38, 39]. In humans, studies of the effects of training on lung volumes have been performed both in boys and girls, pre- and postpubertal, tested either cross-sectionally or longitudinally.

Among physical activities, swimming has been the most extensively studied and appears to be the only one associated with a marked increase in lung volumes.

Effect of swimming on lung volumes in children and young adults

Since the early 1960s, it has been repeatedly observed that lung volumes are larger in young swimmers [40-51]. This has been reported in all cross-sectional and longitudinal studies except one [50]. One study reported lung volume measurements at the start of swimming training in boys aged 10 yrs. Lung volumes were already increased, suggesting that large lungs may be a requirement for becoming a top swimmer [43].

All of the other studies have been performed after more than $1 \mathrm{yr}$ of training. The youngest group, training for more than $1 \mathrm{yr}$ included 7-8 year old girls [48]. In this group, VC, FRC and TLC were significantly greater than in an age-matched control group with similar residual vol- ume (RV)/TLC and FRC/TLC ratios. The increase in lung volumes was more marked in older girls, who had trained longer [48].

Three longitudinal studies have been performed over 1 [49], 3 [40] and 5 yrs [42]. In the 1 yr study [49], the heights of the girl swimmers' were distributed throughout the normal range initially and $1 \mathrm{yr}$ later. In contrast, the values for VC and TLC exceeded the normal range after 1 $\mathrm{yr}$ in 11 out of 17 subjects. In the $3 \mathrm{yr}$ study [40], both boy and girl swimmers were taller at a given age, and the difference between groups became greater in the older children. Swimmers also had larger TLCs as a consequence of larger values for VC. In the $5 \mathrm{yr}$ study [42], in girls with a mean age of $11.5 \mathrm{yrs}$ at the start of the study, VC increased during continued training to a significantly greater extent than expected with regards to the normal growth in height. In this study, some evidence was found for a relationship between the degree and duration of training and the increase in VC.

A group of girl swimmers who had undergone $2.5 \mathrm{yrs}$ of intensive swimming training were the subjects of a follow-up for $10 \mathrm{yrs}$ [44]. When last examined 7 and $10 \mathrm{yrs}$ after the original study, all the girls had given up swimming training. Interestingly, the increased values for VC observed at the first study remained unchanged.

In addition to lung volumes, other lung function parameters have been studied in young swimmers. Maximal static pressures were not significantly increased in prepubertal girl swimmers [48, 49]. Chest wall measurements were noted to be significantly larger in prepubertal girl swimmers compared to controls. Maximal expiratory flow rates (FEV1, maximum mid-expiratory flow rate (MMFR)) were significantly increased both in boy and girl swimm-ers compared to controls, to a similar extent as were VC and TLC [40, 41, 47]. TL,CO at rest has been shown to be increased in trained swimmers compared to controls $[46,47]$, to a similar extent as was TLC. No study has measured alveolar distensibility in child swimmers, but normal alveolar distensibility was reported in young adult swimmers [52]. The finding of a normal alveolar distensibility suggests that large lungs in young adult swimmers could be achieved by an increase in alveolar number [52].

\section{Effects of other sports and of enhanced physical education in children}

The effect of running training on lung volumes has been studied during a short period (4 months) [53] and a long period (26 months) [54] in boys starting training at 11 yrs of age. The short period of running training did not influence TLC. In contrast, the longer period was associated with a significant increase in VC over that expected from the age-dependent increase in body height. Recently, a large controlled study was performed to test the impact of an enhanced physical education programme upon FVC in primary school children during 6 yrs of follow-up from 7-12 yrs of age [55]. Physical activity was enhanced by a vigorous experimental programme of $5 \mathrm{~h}$ of additional physical education per week, taught by a specialist. The enhanced physical education programme had a small positive effect upon the FVC, averaging 3.2\% across all 6 yrs. 


\section{Effects of sporting activity in adults}

It was reported that lung volumes were not increased in young adult runners in contrast to observations in young adult swimmers [52]. Lung volumes were not affected by rowing activity in adults [56].

\section{Effects of ventilatory muscle training in adults}

Lung volumes have been studied after training programmes which were limited to the ventilatory muscles in young adults [57, 58]. Five weeks of ventilatory muscle strength training over the entire $\mathrm{VC}$ range led to only a small increase in $\mathrm{VC}$, despite more than a $50 \%$ increase in maximal static inspiratory pressures at FRC [57]. The small increase in VC could be explained by lung stiffness at large volumes. Another study showed that normal subjects can increase their VC and TLC over a 6 week training period by performing multiple daily sustained inhalations to TLC [58]. The increase in lung volumes could be attri-buted to greater maximal shortening of the inspiratory muscles [58]. Such a mechanism could explain the in-crease in VC in breathholding divers [59].

\section{Effect of altitude on lung volumes}

No consistent differences in lung volumes (TLC, VC, FRC and RV) attributable solely to altitude have been uncovered in studies of residents at altitudes from sea level to $1,800 \mathrm{~m}$ [60-62]. Increases in lung volumes are, however, a part of the adaptive response to high altitudes (at $\breve{S} 3,000 \mathrm{~m}$ ). The effects of altitudes between 1,800 and $3,000 \mathrm{~m}$ on lung volumes are unknown.

Hypoxia occurs at high altitudes because of the reduced partial pressure of oxygen in the atmosphere. The adaptive mechanisms used to compensate for this hypoxia are dependent on the altitude, on whether the exposure to high altitude is temporary or prolonged, and on whether the individual acclimatized during growth. Pulmonary adaptations in residents at high altitudes classically include hyperventilation, increases in $T \mathrm{~L}, \mathrm{CO}$, polycythaemia, and increases in lung volumes. Detailed reviews of all the adaptations to high altitude are available [63-66].

Studies consistently show larger measured lung volumes in natives of high altitudes, which are not explained by race or body size [63, 65, 67-69]. The most commonly reported volume in these studies is $\mathrm{VC}$, but studies also show increases in TLC, FRC and RV in high altitude natives.

The magnitude of the increases in lung volume is hard to quantify because of differences in body size and race of the subjects and the variability between studies. Average increases in TLC in highland natives compared to lowland natives range $7-15 \%$. Compared to the changes in TLC, the increases in VC are smaller and those of FRC and RV larger.

In residents of high altitude, the increase in lung volume varies depending upon when the acclimatization occurred and the duration of the exposure to high altitude. Increase in VC are about the same for individuals who acclimatized and lived at high altitude during growth regardless of whether or not they were born at high altitude $[63,65,70]$. Lowlanders who acclimatize to high altitude as adults have smaller VCs than highland natives.

High altitude children aged $>5$ yrs had larger VCs than lowlanders $[70,71]$. The differences between VCs of highlanders and lowlanders increased until $21 \mathrm{yrs}$ of age [70]. VC did not appear to change if the stay at high altitude was less than 3 yrs [70]. This information suggests that the larger lung volumes in native highlanders is acquired as a result of exposure to hypoxia during growth, rather than being genetically determined. One morphometric study of the lungs of five native highlanders found an increase in the number and size of the alveoli in comparison with sea level controls [72]. The larger lung volumes seen in high altitude natives are not accompanied by increased rates of airflow [16].

No measurement of lung volume is available in infants born at high altitude. MORTOLA et al. [73] reported increa-sed compliance of the respiratory system $(C \mathrm{rs})$ in healthy fullterm infants born in La Paz, Bolivia. This increase was not found in an ethnically similar group of newborns living at low altitude. This increased in $C \mathrm{rs}$, reflecting changes in lung structural and mechanical properties found at birth in populations living at high altitude, is probably not a genetic characteristic, and is most likely the result of foetal hypoxia.

Studies in animals support the hypothesis that changes in lung volumes are acquired [65, 74]. In a study of the effect of high altitude on beagles, JoHnson et al. [74] point out that the increased lung volumes in animals raised at high altitudes are associated with an increase in the fine septal tissue and the internal surface area of the lung (Johnson, 1992 personal communication). Studies of newborn rats exposed to hypoxia found an increase in the number and size of alveoli [17]. Thus, the larger lung volumes seen in high altitude natives appear to be the result of accelerated and/or prolonged lung growth in response to a hypoxaemic stimulus at an early age rather than overinflation (stretching) of the lung. The finding that flows are not increased [16] and the information that only the fine septal tissues increased in beagles acclimatized during growth [74] are consistent with dysynaptic lung growth, in which the airways do not participate in the adaptation to altitude.

Changes in chest configuration are not as well-documented as the changes in lung volume. Peruvians native to high altitude regions are described as having larger and more prominent chests, with larger chest circumferences than Peruvian lowlanders [65]. These findings are, however, not consistent across high altitude populations and are specifically not seen in Asiatic highlanders [65]. JOHNson et al. [74] found beagles raised in Leadville, CO, USA had larger lung volumes, at any given transpulmonary pressure, than beagles raised at lower altitudes, but saw no change in chest configuration. The larger lung volumes were accommodated by a lower diaphragm.

The findings concerning changes in lung volumes associated with acute exposure to high altitudes are variable. A reasonable summary is that, on average, VC decreases (about $200 \mathrm{~mL}$ in adults) and TLC and RV increase with the initial exposure to altitude but return to baseline values within a month $[63,75,76]$. 


\section{Effects of sleep on lung volumes}

The only comparative measurements of lung volumes during wakefulness and sleep concern FRC in supine adults and newborns.

\section{Data available in adults}

In eight healthy male adults (aged 21-41 yrs), FRC has been measured using the helium dilution technique. FRC fell significantly from wakefulness to non-rapid eye move-ment (NREM) (stage 3/4) and rapid eye movement (REM) sleep by 9.9 and $10 \%$, respectively. No significant difference was observed between NREM (stage 3/4) and REM sleep [77].

In five healthy male adults, aged 23-33 yrs, FRC has been measured using a horizontal body plethysmograph [78]. FRC fell significantly from wakefulness to all states of sleep. FRC fell by an average of $13-15 \%$ in NREM, stage 2, 3/4 and $16.5 \%$ in REM sleep. In REM sleep, the fall in FRC was nonsignificantly different from that in NREM sleep, in contrast to that observed in asthmatic adult patients in whom FRC significantly decreased [78].

\section{Data available in newborns}

The potential influence of active (REM) versus quiet (NREM) sleep on the end-expiratory lung volume, FRC, remains controversial. Two studies have assessed changes in FRC in active as compared to quiet sleep, using inductance plethysmography to detect changes in anteroposterior diameters both of rib cage and abdomen in preterm infants [79], and alterations in the baseline signal from a respiratory jacket in term infants [80]. In both studies, FRC was found to fall slightly during the transition from quiet to active sleep, although in the healthy term infants FRC recovered to previous levels within 20-40 s [80].

Two studies using a body plethysmograph have reported a significant fall in FRC in active compared to quiet sleep in healthy full-term newborns [81, 82]. The mean fall in FRC was $31 \%$ in six infants and $12 \%$ in eight. There may be methodological rather than purely physiological explanations for these differences, including lack of support of the upper airways [81, 82]. Three studies have measured FRC using the helium dilution technique during active and quiet sleep assessed by neurophysiological criteria [83-86]. In healthy full-term newborns, no significant changes in FRC were observed, related either to sleep state or regularity of respiration; however, no attempt was made to measure rib cage and abdominal motion [83].

Two studies have concerned both preterm and full-term newborns, and showed no change in FRC in relation to change in sleep state, but a fall in FRC only when rib cage and abdominal motion were $180^{\circ}$ out of phase, regardless of sleep state $[84,85]$.

Discrepancies between these different studies may be related to the method of measurement. Using body plethysmography, repeat measurements of FRC can be achieved over much shorter time periods than when using helium to wash out the lungs between repeat measurements. If there is a rapid recovery in FRC following any reductions during active sleep [80], any sleep-related changes in FRC may be detected by plethysmography but missed using helium dilution techniques. However, as stated above, the magnitude of changes during plethysmographic measurements may have been overestimated due to poor equilibration of airway pressures during airway occlusion in active sleep [81].

For routine practice, it is recommended that functional residual capacity be measured during quiet sleep, when breathing is regular and when rib cage and abdominal motion are in phase [86]. In preterm infants and neonates, who manifest periods of paradoxical rib cage motion during quiet sleep and a large proportion of active sleep, measurement of functional residual capacity when rib cage and abdominal movements are in phase is difficult.

\section{References}

1. Faridy EE. Effect of maternal malnutrition on surface activity of fetal lungs in rats. J Appl Physiol 1975; 39: 535-540.

2. Das RM. The effects of intermittent starvation on lung development in suckling rats. Am J Pathol 1984; 177: 326-332.

3. Kalenga M, Henquin JC. Protein deprivation from the neonatal period impairs lung development in the rat. Pediatr Res 1988; 21: 45-49.

4. Kalenga M, Eeckhout Y. Effects of protein deprivation from the neonatal period on lung collagen and elastin in the rat. Pediatr Res 1989; 26: 125-127.

5. Kalenga M, Henquin JC. Alteration of lung mechanics by protein-calorie malnutrition in weaned rats. Respir Physiol 1987; 68: 29-39.

6. Kalenga M, Tschanz SA, Burri PH. Protein deficiency and the growing rat lung. I. Nutritional findings and related lung volume. Pediatr Res 1995; 37: 783-788.

7. Kalenga M, Tschanz SA, Burri PH. Protein deficiency and the growing rat lung. II. Morphometric analysis and morphology. Pediatr Res 1995; 37: 789-795.

8. Lechner AJ. Perinatal age determines the severity of retarded lung development induced by starvation. Am Rev Respir Dis 1985; 131: 638-643.

9. Lechner AJ. Perinatal age determines the severity of retarded lung development induced by starvation. Am Rev Respir Dis 1985; 131: 638-643.

10. Gaultier $\mathrm{Cl}$, Harf A, Balmain N, Cuisinier-Gleizes P, Mathieu H. Lung mechanics in rachitic rats. Am Rev Respir Dis 1984; 130: 1108-1110.

11. Chan KN, Noble-Jamieson CM, Ellman A, Bryan EM, Silverman M. Lung function in children of low birth weight. Arch Dis Child 1989; 64: 1284-1293.

12. Rona RJ, Gulliford MC, Chinn S. Effects of prematurity and intrauterine growth on respiratory health and lung function in childhood. BMJ 1993; 306: 817-820.

13. Langston C, Kida K, Reed M, Thurlbeck WM. Human lung growth in late gestation and in the neonate. $\mathrm{Am} \mathrm{Rev}$ Respir Dis 1984; 129: 607-613.

14. Keely FW, Fagan DG, Webster SI. Quantity and character of elastin in developing human lung parenchymal tissues of normal infants and infants with respiratory distress syndrome. J Lab Physiol 1981; 3: 557-564.

15. Thurlbeck WM. Postnatal human lung growth. Thorax 1982; 37: 564-571.

16. Zeltner TB, Burri P. The postnatal development and growth of the human lung. II. Morphology. Respir Physiol 1987; 3: 557-564. 
17. Brody JS, Vaccaro C. Postnatal formation of alveoli: interstitial events and physiologic consequences. Fed Proc 1979; 38: 215-223.

18. Brody JS, Lahiri M, Simpser M, Motoyama ED, Velasquez T. Lung elasticity and airway dynamics in Peruvians native to high altitude. J Appl Physiol 1977; 42: 245-251.

19. Cunningham EL, Brody JS, Jain BP. Lung growth induced by hypoxia. J Appl Physiol 1974; 37: 362-366.

20. Primhak R, Coates FS. Malnutrition and peak expiratory flow rate. Eur Respir J 1988; 1: 801-803.

21. Murciano D, Rigaud D, Pingleton S, Armengaud MH, Melchior JC, Aubier M. Diaphragmatic function in severely malnourished patients with anorexia nervosa. Am J Respir Crit Care 1994; 150: 1569-1574.

22. Raven PB, Taguchi S, Drinkwater BL, Kaneko M, Horvath SM, Matsui $\mathrm{H}$. Anthropometric, spirometric, and physiologic comparisons of migrant Japanese. Hum Biol 1974; 46: 483-494.

23. Massey DG, Fournier-Massey G. Japanese-American pulmonary reference value: influence of environmental on anthropology and physiology. Environ Res 1986; 39: 418-433.

24. Inselman LS, Wapnir RA, Spencer H. Obesity-induced hyperplastic lung growth. Am Rev Respir Dis 1987; 135: 613-616.

25. Inselman LS, Padilla-Burgos B, Teichberg S, Spencer H. Alveolar enlargement in obesity-induced hyperplastic lung growth. J Appl Physiol 1988; 65: 2291-2296.

26. Chaussain M, Gamain B, La Torre AM, Vaida P, de Lattre J. Respiratory function at rest in obese children. Bull Eur Physiopathol Respir 1977; 13: 599-609.

27. Bosisio E, Sergi M, Di Natale B, Chiu-Mello G. Ventilatory volumes, flow rates, transfer factor and its components (membrane component, capillary volume) in obese adults and children. Respiration 1984; 45: 321-326.

28. Inselman LS, Milanese A, Deurloo A. Effect of obesity on lung function in children. Pediatr Pulmonol 1993; 16 : $130-137$.

29. Gaultier Cl, Gourmelen M, Boule M, Allaire Y, Girard F. Fonction pulmonaire et retard de croissance lié ou non à un déficit hypophysaire. Bull Eur Physiopathol Respir 1977; 13: 487-497.

30. Mansell AL, Levison H, Bailey JD. Maturation of lung function in children with hypopituitarism. Am Rev Respir Dis 1983; 127: 166-170.

31. Jain BP, Brody JS, Fischer AB. The small lung of hypopituitarism. Am Rev Respir Dis 1973; 108: 49-55.

32. Brody JS, Fischer AB, Gocmen A, Dubois AB. Acromegalic pneumonomegaly: lung growth in the adult. $J$ Clin Invest 1970; 49: 1051-1060.

33. De Troyer A, Desir D, Copinschi G. Regression of lung size in adults with growth hormone deficiency. $Q \mathrm{~J} \mathrm{Med}$ 1980; 69: 329-340.

34. Donnelly PM, Grunstein RR, Peat JK, Woolcock AJ, Bye PTP. Large lungs and growth hormone: an increased alveolar number. Eur Respir J 1995; 8: 938-947.

35. Gaultier C, Harf A, Girard F. Lung mechanics in growing guinea-pigs treated with growth hormone. J Dev Physiol 1986; 8: 315-321.

36. Bartlett D. Postnatal growth of the mammalian lung: influence of excess growth hormone. Respir Physiol 1971; 12: 297-304

37. Brody JS, Buhain WJ. Hormone-induced growth of the adult lung. Am J Physiol 1972; 223: 1444-1450.

38. Bartlett D, Areson JG. Quantitative lung morphology in Japanese waltzing mice. J Appl Physiol: Respirat Environ Exercise Physiol 1978; 44: 446-449.
39. Geelhaar A, Weibel ER. Morphometric estimation of pulmonary diffusing capacity. III. The effect of increased oxygen consumption in Japanese waltzing mice. Respir Physiol 1971; 11: 354-366.

40. Andrew GM, Becklake MR, Guleria JS, Bates DV. Heart and lung functions in swimmers and non athletes during growth. J Appl Physiol 1972; 32: 245-251.

41. Astrand PO, Engstrom I, Eriksson BO, et al. Girl swimmers with special reference to respiratory and circulatory adaptation and gynaecological and psychiatric aspects. Acta Paediatr Scand 1963; Suppl. 147: 43-75.

42. Engstrom I, Eriksson BO, Karlberg P, Saltin B, Thoren C. Preliminary report on the development of lung volumes in young girls swimmers. Acta Paediatr Scand 1977; Suppl. 217: 73-76.

43. Ericksson BO, Berg K, Taranger J. Physiological analysis of young boys starting swim-training. In: Eriksson BO, Furberg B, eds. Swimming Medicine. IV. Baltimore, University Park Press, 1978.

44. Ericksson BO, Engstrom I, Karlberg P, Lundin A, Baltin $\mathrm{B}$, Thoren $\mathrm{C}$. Long-term effect of previous swim-training in girls: a 10-year follow-up of the "girl swimmers". Acta Paediatr Scand 1978; 67: 285-292.

45. Jones ADG, Helms P. Does swimming improve lung funtion? British Paediatric Respiratory Group, Birmingham, UK, Sept 22-23, 1989.

46. Newman F, Smalley BF, Thompson ML. A comparison between body size and lung function of swimmers and normal school children. J Physiol (Lond) 1961; 156: 910.

47. Vaccaro P, Clarke DH, Morris AF. Physiological characteristics of young well-trained swimmers. Eur J Appl Physiol 1980; 40: 61-66.

48. Zinman R, Gaultier C. Maximal static pressures and lung volumes in young female swimmers. Respir Physiol 1986; 64: 229-239.

49. Zinman R, Gaultier C. Maximal static pressures and lung volumes in young female swimmers: one year follow-up. Pediatr Pulmonol 1987; 3: 145-148.

50. Ness GW, Cunningham DA, Eynon RE, Shaw DB. Cardiopulmonary function in prospective competitive swimmers and their parents. J Appl Physiol 1974; 37: 27-31.

51. Magel JR, Andersen KL. Pulmonary diffusing capacity and cardiac output in young trained Norwegian swimmers and untrained subjects. Med Sci Sports 1969; 1: 131-139.

52. Armour J, Donnely PM, Bye PTP. The large lungs of elite swimmers: an increased alveolar number? Eur Respir $J$ 1993; 6: 237-247.

53. Dobeln W, Eriksson BO. Physical training, maximal oxygen uptake and dimensions of the oxygen transporting and metabolizing organs in boys 11-13 years of age. Acta Paediatr Scand 1972; 61: 653-660.

54. Ekblom B. Effect of physical training in adolescent boys. J Appl Physiol 1969; 27: 350-355.

55. Shephard RJ, Lavallee H. Effects of enhanced physical education on lung volumes of primary school children. $J$ Sports Med Phys Fitness 1996; 36: 186-194.

56. Biersteker MWA, Bierteker PA. Vital capacity in trained and untrained healthy young adults in the Netherlands. Eur J Appl Physiol 1985; 54: 46-53.

57. Leith DE, Bradley M. Ventilatory training and endurance. J Appl Phsyiol 1976; 41: 508-516.

58. Fanta CH, Leith DE, Brown R. Maximal shortening of inspiratory muscles: effect of training. J Appl Physiol: Respirat Environ Exercise Physiol 1983; 54: 1618-1683.

59. Tatal K. Comparisons of ventilatory capacities among 
fishing divers, nurses and telephone operators in Japanese females. Jpn J Physiol 1975; 7: 37-41.

60. Goldman HI, Becklake MR. Respiratory function tests: normal values at median altitude and the prediction of normal results. Am Rev Thor Pulm Dis 1969; 79: 457467.

61. Cotes JE, Sounders MJ, Adam JER, Anderson HR, Hall AM. Lung function in costal and highland New Guineans: comparison with Europeans. Thorax 1973; 28: 320-330.

62. Crapo RO, Morris AH, Clayton PD, Nixon CR. Lung volumes in healthy nonsmoking adults. Bull Eur Physiopathol Respir 1982; 18: 419-425.

63. Frisancho AR. Functional adaptation to high altitude hypoxia. Science 1975; 187: 313-319.

64. Hurtado A. Animals in high altitudes: resident man. In: Dill DB, Adloph EF, Wilber CG, eds. Handbook of Physiology. Section 4. Adaptation to the Environment. Washington, DC, American Physiological Society, 1964; pp. 843-860.

65. Heath D, Williams DR. Man at High Altitude: The Pathophysiology of Acclimatization and Adaptation. 2nd Edn. New York, Churchill Livingstone, 1981.

66. Lenfant C, Sullivan K. Adaptation to high altitude. $N$ Engl J Med 1971; 284: 1298-1309.

67. Hurtado A. Some physiologic and clinical aspects of life at high altitudes. In: Cander L, ed. Aging of the Lung: Perspectives. New York and London, Grune \& Stratton, 1964; pp. 257-278.

68. De Graff AC, Grover RF, Johnson RL, Hammon JW, Miller JM. Diffusing capacity of the lung in Caucasians native to 3,100 m. J Appl Physiol 1970; 29: 71-76.

69. Greksa LP, Spielvogel H, Paz-Zamora M, Caceres E, Paredes-Fernandez L. Effect of altitude on the lung function of high altitude residents of European ancestry. Am J Phys Anthropol 1988; 75: 77-85.

70. Lahiri S, De Laney RG, Brody JS, et al. Relative rote of environmental and genetic factors in respiratory adaptation to high altitude. Nature 1976; 261: 133-135.

71. Villena M, Spielvogel H, Vargas E, et al. Anthropometry and lung function of 10 to 12 year old Bolivian boys. Int $J$ Sports Med 1994; 15: 575-578.

72. Saldana M, Oyola G. Morphometry of the high altitude lung. Lab Invest 1970; 22: 509-512.

73. Mortola JP, Rezzonico R, Fischer JT, et al. Compliance of the respiratory system in infants born at high altitude. Am Rev Respir Dis 1990; 142: 43-48.

74. Johnson RL, Cassidy SS, Grover RF, Schutte E, Epstein
RH. Functional capacities of lungs and thorax in beagles after prolonged residence at $3,100 \mathrm{~m}$. J Appl Physiol 1985; 59: 1773-1782.

75. Tenney SM, Rahn H, Stroud RC, Mithoefer JC. Adaptation to high altitude: changes in lung volumes during the first seven days at Mt Evans, Colorado. J Appl Physiol 1953; 5: 607-613.

76. Saunders NA, Betts MF, Pengelly LD, Rebuck AS. Changes in lung mechanics induced by acute isocapnic hypoxia. J Appl Physiol 1977; 42: 413-419.

77. Hudgel D, Devadatta P. Decrease in functional residual capacity during sleep in normal humans. J Appl Physiol: Respirat Environ Exercise Physiol 1984; 57: 1319-1322.

78. Ballard RD, Irvin CG, Martin RJ, Pak J, Pandey R, White DP. Influence of sleep on lung volume in asthmatic patients and normal subjects. J Appl Physiol 1990; 68: 2034-2041.

79. Lopes J, Muller NL, Bryan MH, Bryan AC. Importance of inspiratory muscle tone in maintenance of FRC in the newborn. J Appl Physiol: Respirat Environ Exercise Physiol 1981; 51: 830-834.

80. Stokes GM, Milner AD, Newball EA, Smith NJ, Dunn C, Wilson AJ. Do lung volumes change with sleep state in the neonate? Eur J Pediatr 1989; 148: 360-364.

81. Henderson-Smart DJ, Read DJC. Reduced lung volume during behavioural active sleep in the newborn. $J$ Appl Physiol: Respirat Environ Exercise Physiol 1979; 46: 1081-1085.

82. Stokes GM, Milner AD, Vyas H, Hopkin IE. Lung volumes in full-term neonates during active and quiet sleep. In: Rolfe P, ed. Neonatal Physiological Measurements. London, Butterworth Press, 1986; pp. 275-277.

83. Beardsmore CS, MacFadyen UM, Moosavi SSH, Wimpress SP, Thompson J, Simpson H. Measurement of lung volumes during active and quiet sleep in infants. Pediatr Pulmonol 1989; 7: 71-77.

84. Moriette G, Chaussain M, Radvanyi-Bouvet MF, Walti H, Pajot N, Relier JP. Functional residual capacity and sleep states in the premature newborn. Biol Neonate 1983; 43: 125-133.

85. Walti H, Moriette G, Radvanyi-Bouvet MF, et al. Influence of breathing pattern on functional residual capacity in sleeping newborn infants. J Dev Physiol 1986; 8: 167-172.

86. Gaultier C, Fletcher ME, Beardsmore C, England S, Motoyama E. Respiratory function measurements in infants: measurement conditions. Eur Respir J 1995; 8: 1057-1066. 